\title{
Randomised clinical trial of lensectomy versus lens aspiration and primary capsulotomy for children with bilateral cataract in south India
}

\author{
Michael Eckstein, P Vijayalakshmi, Clare Gilbert, Allen Foster
}

\begin{abstract}
Aims-The primary objective was to determine which surgical technique gave the best long term visual outcome for infants and young children with bilateral symmetrical cataract in south India. Secondary objectives were to assess complications and the need for further surgical intervention.

Methods-A randomised controlled clinical trial was undertaken. 65 children under 10 years old with bilateral cataract had one eye treated by lensectomy and the other by aspiration with primary capsulotomy.

Results-56 children (86\%) with a mean age at surgery of 53 months were reviewed 3 years after surgery. The overall binocular acuity was $6 / 18$ or better in $57.1 \%$ and $6 / 60$ or better in $94.6 \%$. There was no difference in visual acuity between the matched pairs of eyes undergoing aspiration or lensectomy at the third year of follow up $(p=0.57)$. Aspiration eyes were more likely to require a secondary procedure to restore vision than lensectomy eyes $(66.1 \%$ v $1.8 \%)$.

Conclusion-Aspiration with primary capsulotomy gives an acceptable visual outcome in this part of India providing that there is good follow up to manage capsule opacification. If secondary intervention is not possible owing to poor compliance with follow up, then lensectomy is likely to give better long term visual rehabilitation providing there is good maintenance and technical support for the lensectomy equipment.

(Br f Ophthalmol 1999;83:524-529)
\end{abstract}

Ophthalmology,

Madurai, Tamil Nadu, India

M Eckstein

P Vijayalakshmi

Department of

Preventive

Ophthalmology,

Institute of

Ophthalmology,

London

M Eckstein

C Gilbert

A Foster

Correspondence to:

Dr Allen Foster, Institute of

Ophthalmology, 11 Bath

Street, London EC1V 9EL

Accepted for publication

10 November 1998

Bilateral childhood cataract in south India is a significant cause of childhood blindness accounting for an estimated 200000 cases. $^{1}$ Clinic attendance is often delayed and significant amblyopia is likely to develop before surgery can be performed to clear the visual axis. $^{2}$ Children and their parents are often unable to attend for follow up appointments or for secondary surgical procedures because of the large distances and expenses involved. ${ }^{3}$ In this region the most appropriate surgical technique has yet to be defined and the choice is limited because microsurgical equipment is expensive and paediatric ophthalmic surgical experience and anaesthesia are spread unevenly throughout the country.
In south India most cataracts in children under 10 years old are removed by aspiration of the lens, with or without a primary posterior capsulotomy. Lensectomy may be a more appropriate procedure because the posterior capsule and anterior vitreous are completely removed at the time of surgery avoiding the complication of posterior capsule opacification. It does however require more sophisticated equipment and expertise and may have a higher complication rate.

This study was designed to determine whether lensectomy might be a better treatment option for children with bilateral cataract in a developing country such as India by comparing visual outcome and complications between the two procedures.

\section{Methods}

Children with bilateral cataracts significantly affecting vision had one eye randomised to undergo either a lensectomy procedure or an aspiration with a primary capsulotomy. The second eye automatically had the alternative procedure. Each child therefore had a different procedure on each eye. Children were randomly assigned treatment both to the eye to be operated on first and the procedure to be performed (aspiration or lensectomy). Allocation was concealed in opaque, sealed envelopes and the randomisation was generated by computerised random number software (SAS).

To be eligible for inclusion in the trial children had to be aged $0-10$ years inclusive, live in the state of Tamil Nadu or the neighbouring state of Kerala, and have bilateral symmetrical cataracts, both requiring surgery, and each eye amenable to lensectomy or aspiration with a primary posterior capsulotomy. If the visual acuity was measurable then the acuity in each eye had to be within 0.3 thesia, those with mental retardation, so that postoperative acuity would be difficult to accurately determine, and those with pre-existing ocular diseases were excluded.

The primary aim was to determine which procedure gave the best long term (minimum 3 year follow up) visual outcome. Secondary objectives were to define the frequency and cause of operative, early postoperative, and late complications in the two techniques and to compare secondary surgical intervention rates within 3 years of the initial procedure. The study has been designed to continue follow up for 10 years in order to determine the 
incidence of glaucoma and other late complications such as retinal detachment.

Children were recruited from the Aravind Eye Hospital paediatric eye clinic in Tamil $\mathrm{Nadu}$, south India. Informed consent was obtained from all parents and the study protocol was approved by the ethics committee of the Aravind Eye Hospital and the Government of India Medical Research Council.

PREOPERATIVE AND POSTOPERATIVE EXAMINATION Whenever possible children were examined on the slit lamp microscope and by direct and indirect ophthalmoscopy after pupil dilatation. If slit lamp examination was not possible a torch and loupe was used. Intraocular pressures were measured using the Keeler Pulsair or Goldmann tonometer. Children who appeared systemically unwell or who had other physical abnormalities were examined by a paediatrician and an anaesthetist. Cataracts were photographically documented by a camera mounted on the operating microscope.

Visual acuity was measured using Keeler acuity cards, Cardiff cards, Cambridge crowding cards, or Snellen acuity charts depending on the child's age, vision, and ability. A visual function battery was used in infants with very poor vision. ${ }^{4}$ All acuity measurements were converted to log MAR units for data entry and analysis. A single trained examiner who was masked to the treatment performed all visual acuity tests. Children were refracted by a trained optometrist before discharge and at each outpatient follow up appointment.

Complications were recorded on a customised proforma: iritis was defined as being present if there were more than 50 cells visible in a $2 \times 1 \mathrm{~mm}$ slit beam at 45 degrees of oblique illumination. Opacification of the posterior capsule (PCO) was classified into three types: type 1, PCO not seen in the central visual axis, but seen through a dilated pupil with direct ophthalmoscopy giving a clear view of the fundus; type 2, PCO seen in the central visual axis in an undilated pupil, fundus details only minimally obscure; type $3, \mathrm{PCO}$ is seen in the central visual axis in an undilated pupil, fundus details cannot be clearly made out. Glaucoma was recorded if the intraocular pressure (IOP) was $>21 \mathrm{~mm} \mathrm{Hg}$ and the optic disc showed signs of progressive cupping or if the IOP was consistently higher than $26 \mathrm{~mm}$ $\mathrm{Hg}$.

To ensure adequate follow up a series of incentives was used which included free treatment including spectacles, travel expenses for all visits, and reimbursement for lost parental earnings. Parents were contacted by post 2 weeks before each visit became due. If they failed to turn up a second letter was sent. Parents and children who failed to turn up after the second letter, were traced by a social worker and personally asked to return to the hospital.

SURGICAL PROCEDURE

All surgery was performed under general anaesthesia by a single paediatric ophthalmologist (PV), who was experienced with both sur- gical procedures. Preoperatively, pupils were dilated with phenylephrine $2.5 \%$ and cyclopentolate $1 \%$. The ocular adnexa and skin surrounding the eye were cleaned with 5\% povidone-iodine, the surgical field draped with sterile towels, and the eye irrigated with sterile saline solution. A lid speculum was inserted and a superior rectus suture attached.

\section{Lensectomy technique}

A small conjunctival flap was created and a 3 $\mathrm{mm}$ limbal incision was made. A peripheral iridectomy was created and an MVR blade passed through the iridectomy, cutting the capsule and mobilising the lens material. The lensectomy cutter (Peyman Vitreophage) was inserted and the entire lens contents removed along with a portion of the anterior vitreous. The anterior chamber was maintained with Ringer's solution. The section was closed with two 10-0 nylon sutures, which were not routinely removed, and gentamicin $5 \mathrm{mg}$ was injected subconjunctivally into the lower fornix.

\section{Aspiration technique}

A small conjunctival flap was created and a 3 $\mathrm{mm}$ limbal incision was made. An irrigating cystotome was inserted into the anterior chamber and a circular "can opener" type capsulotomy produced. Ringer lactate solution was used as the intraocular irrigating solution. A Simcoe irrigation aspiration cannula was used to remove the lens material. A superior peripheral iridectomy was produced and the section closed with two 10-0 nylon sutures. The cystotome on the end of a syringe of air was re-inserted into the eye through the same incision between the sutures and after filling the chamber with air, a small perforation in the posterior capsule at the six o'clock position was made. With the anterior chamber maintained with air to keep the vitreous face back, the cystotome tip was turned slightly to one side and the posterior capsule drawn up leaving a central opening. Gentamicin $5 \mathrm{mg}$ was injected subconjunctivally into the lower fornix.

A combination of gentamicin $0.3 \%$ and Betnesol $1.5 \%$ were normally given four times a day to the operated eye after the first postoperative examination. Surgery was performed on the second eye during the same admission whenever possible. The first eye was not occluded in the interval between operation on the first and second eye. Children were refracted and given aphakic spectacles after surgery had been completed to both eyes.

STUDY END POINT AND STATISTICAL ANALYSIS The study was designed with matched pairs, so that results were compared between eyes of the same child. The $\chi^{2}$ test was used to compare binary aspects of patient data. The significance level was set at $\mathrm{p}<0.05$. McNemar's $\chi^{2}$ test and the paired $t$ test were used to analyse matched pair data. ${ }^{5}$ Two way analysis of variance (ANOVA related sample comparison) was performed to compare visual acuity expressed as $\log$ MAR scores between the two eyes as well as to assess acuity change over time. Results were 
Table 1 Snellen equivalents of preoperative, 1 , and 3 year postoperative binocular acuity for all children

\begin{tabular}{|c|c|c|c|c|c|c|}
\hline \multirow[b]{2}{*}{ Snellen equivalent } & \multicolumn{2}{|c|}{ Preop } & \multicolumn{2}{|c|}{1 year postop } & \multicolumn{2}{|c|}{3 years postop } \\
\hline & No & $\%$ & No & $\%$ & No & $\%$ \\
\hline $6 / 6-6 / 18$ & 0 & 0 & 24 & 40 & 32 & 57.1 \\
\hline$<6 / 18-6 / 60$ & 15 & 23.1 & 28 & 46.7 & 21 & 37.5 \\
\hline$<6 / 60-3 / 60$ & 6 & 9.2 & 5 & 8.3 & 2 & 3.6 \\
\hline$<3 / 60$ & 44 & 67.7 & 3 & 5 & 1 & 1.8 \\
\hline Total & 65 & 100 & 60 & 100 & 56 & 100 \\
\hline
\end{tabular}

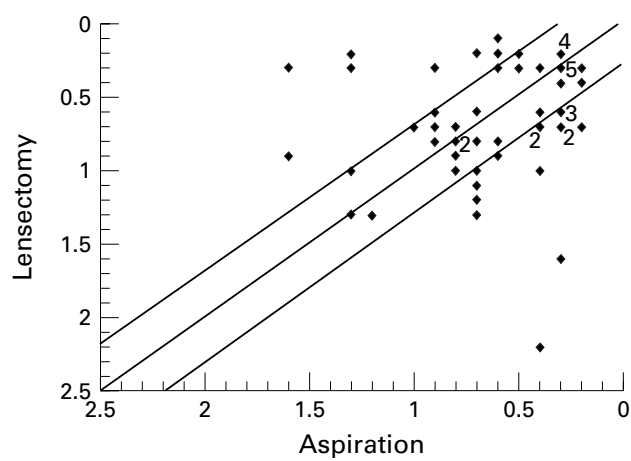

Figure 1 Graph of uniocular log MAR acuity comparing vision in lensectomy and aspiration eyes in the same child 3 years after surgery (matched pair data). Points above the line of equality have better acuity in lensectomy eye compared with aspiration eye (56 children). The numbers are overlapping points.

analysed on an intention to treat basis even if it was not possible to complete the randomised procedure as planned.

\section{Results}

STUDY GROUP CHARACTERISTICS

Over a 9 month period in 1993-4, 127 children aged $0-10$ years with bilateral cataract attended the paediatric eye clinic for the first time. Of these children, 65 (31 boys and 34 girls) fulfilled the entry criteria and were enrolled into the clinical trial. Of the 62 children who were ineligible to enter the trial, three children lived in states other than Tamil Nadu or Kerala (so that the distances were considered too great for long term follow up); 33 children had cataracts which were not symmetrical or had other associated ocular disease; and 22 children were excluded because management other than lensectomy or aspiration without an intraocular lens was felt to be more appropriate. A further four children were judged too small for safe general anaesthesia and surgery was deferred until a later date.

The 65 children who entered the study had a mean age of 53 months (range 3 months -10 years); $84 \%$ came from Tamil Nadu, $16 \%$ from Kerala, and the majority $(74 \%)$ were from rural areas.

At presentation, 35 children (54\%) had nystagmus. Nystagmus was more common in children less than 5 years old $(p=0.07)$ and in those who had total cataracts $(p=0.02)$. Forty children $(62 \%)$ had a manifest strabismus at presentation (esotropia 50\%, exotropia 50\%).

The aetiology of cataract was autosomal dominant (18 cases), autosomal recessive (two), congenitally acquired rubella (four), and idiopathic (41). The cataracts had similar mor-
Table $2 \log M A R$ uniocular acuity at 3 year follow up, for 56 children, by surgical technique

\begin{tabular}{llll}
\hline & $\begin{array}{l}\text { Aspiration with } \\
\text { primary capsulotomy }\end{array}$ & & Lensectomy \\
\cline { 2 - 2 } $\log$ MAR acuity & No (\%) & No (\%) \\
\hline $0-0.5$ & $26(46.4)$ & $23(41.1)$ \\
$<0.5-1.0$ & $23(41.1)$ & & $25(44.6)$ \\
$<1.0-1.5$ & $5(8.9)$ & $1(1.8)$ \\
$<1.5-2.0$ & $2(3.6)$ & $1(1.8)$ \\
$<2.0-2.5$ & 0 & 56 \\
Total & 56 & \\
\hline
\end{tabular}

phology in each pair of eyes; total cataracts (27), nuclear (four), lamellar (22), posterior polar (three), mixed (10).

One child absconded after the first operation and failed to undergo surgery in both eyes. The majority (86\%) had surgery to both eyes completed within 7 days, with the longest interval before the second procedure being 21 days. Eyes were not occluded between operations.

\section{FOLLOW UP}

In the first year three children died (5\%), one child had surgery on only one eye, and one child was lost to follow up, so that 60 of 65 children (91\%) were reviewed. A further four children were lost to follow up by year 3, so that 56 children $(86 \%)$ were available for 3 year follow up evaluation.

VISUAL OUTCOME

The mean binocular acuity (log MAR) for all children at baseline was 1.8 (SE 0.052). Uniocular vision testing was possible in 60 eyes from 30 children giving a mean preoperative acuity of $1.8(0.073)$ in eyes that were randomised for lensectomy, and $1.8(0.072)$ in aspiration eyes. Baseline acuity was often difficult to record accurately because of poor compliance and indistinct endpoints in the preferential looking tests.

By the third year of follow up, $57 \%$ of children obtained a binocular acuity of $6 / 18$ or better and a further $38 \%$ of $6 / 24-6 / 60$. Three children $(5.4 \%$ ) had less than $6 / 60$ binocular vision (Table 1). Figure 1 is a plot of visual acuities at year 3 comparing matched pair data from lensectomy and aspiration eyes. The lines either side of the line of equality indicate a change of plus or minus $0.3 \log$ MAR units. There was no significant difference in the visual acuity between matched pairs (acuity difference between eyes of $0.3 \log$ MAR units) at the 3 year review $(\mathrm{p}=0.57)$ (Table 2$)$.

Because the ability to perform secondary procedures such as a YAG capsulotomy or membranectomy are limited in this area, and because many children would not normally attend for further follow up, the visual acuity data for the two surgical procedures have been analysed hypothesising that children may not come to follow up for management of the opacified capsule. In this case 21 children would have had $0.3 \log$ MAR unit acuity better in their lensectomy eye and six children $0.3 \mathrm{log}$ MAR unit acuity better in their aspiration eye $(p<0.007)$. 
Table 3 Surgical and postoperative complications up to and including 3 year follow up

\begin{tabular}{|c|c|c|c|c|}
\hline \multirow[b]{2}{*}{ Complication } & \multirow{2}{*}{$\begin{array}{l}\text { Lensectomy } \\
\text { No (\%) }\end{array}$} & \multirow{2}{*}{$\frac{E C C E}{N o(\%)}$} & \multirow{2}{*}{$\begin{array}{l}\chi^{2} \\
(M c N e m a r s)\end{array}$} & \multirow[b]{2}{*}{$p$ Value } \\
\hline & & & & \\
\hline \multicolumn{5}{|c|}{ Surgical complications $(n=65)$ at time of procedure: } \\
\hline Machine failure & $8(12.3)$ & 0 & 6.1 & 0.013 \\
\hline Iris trauma & $5(7.6)$ & 0 & 3.2 & 0.07 \\
\hline Lens fragments in vitreous & $5(7.6)$ & 0 & 3.2 & 0.07 \\
\hline Incomplete removal lens cortex & $13(20)$ & $1(1.5)$ & 8.6 & 0.003 \\
\hline \multirow{2}{*}{\multicolumn{5}{|c|}{$\begin{array}{l}\text { Postoperative complications ( } \mathrm{n}=56) \text { up to } 3 \text { year follow up: } \\
\text { Capsule opacification affecting vision }\end{array}$}} \\
\hline $\begin{array}{l}\text { Capsule opacification affecting vision } \\
\text { (type } 2 \text { and } 3 \text { ) }\end{array}$ & & & & $<0.001$ \\
\hline Pupil decentration affecting vision & $2(3.6)$ & $1(1.8)$ & 0.5 & 0.5 \\
\hline Retinal detachment & $2(3.6)$ & 0 & 0.5 & 0.5 \\
\hline Epithelial in growth & 0 & $1(1.8)$ & 0 & 1 \\
\hline Glaucoma & $1(1.8)$ & $1(1.8)$ & 0.5 & 0.5 \\
\hline
\end{tabular}

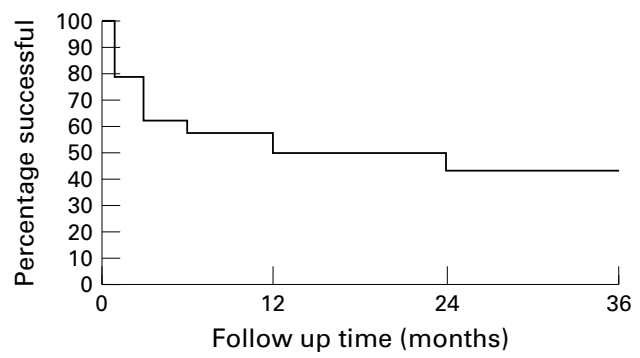

Figure 2 Kaplan-Meier survival analysis following aspiration and primary capsulotomy showing failure (development of type 2 or type 3 opacification) against follow up time.

APHAKIA AND AMBLYOPIA

Aphakia was routinely corrected with spectacles, but 18 of 60 children (30\%) had lost or broken their spectacles by the first year of follow up. At the 3 year review nine of 56 children $(16 \%)$ would not wear spectacles, of which seven had poor vision and spectacles were of limited benefit. Bifocal spectacles were being used by 13 of 56 (23\%) children 3 years after surgery. Treatment for amblyopia with patching was not commonly used because compliance was poor but five children had one eye patched when amblyopia appeared to be progressing during follow up.

\section{COMPLICATIONS}

Lensectomy, compared with aspiration, was significantly associated with failure to remove all of the lens cortex, iris trauma, and loss of lens material into the vitreous. Machine failure was a significant problem in the lensectomy group and a backup machine or a technician were required in eight cases (12\%) (Table 3). Lens aspiration with primary posterior capsulotomy compared with lensectomy was more likely to result in vitreous in the anterior chamber at the end of the procedure.
Two lensectomy eyes (1.8\%) developed a retinal detachment, one noted at the 3 month and the other at the 2 year follow up examination. One eye, which had an aspiration, developed localised epithelial ingrowth from the wound site noted at the 6 month review. Two eyes $(1.8 \%)$ from two different children developed glaucoma between the first and second year of follow up, one in the aspiration group and the other in the lensectomy group (Table 3).

Of the 56 aspiration eyes followed for 3 years 37 required at least one secondary procedure, either YAG capsulotomies or surgical membranectomy, to clear the posterior capsule. Of the 37 eyes which required treatment for capsule opacification, 20 were on eyes randomised to the first eye. One secondary procedure was required in the lensectomy group to remove an anterior capsule which had been inadvertently left behind. The Kaplan-Meier graph in Figure 2 illustrates the failure of the primary capsulotomy and development of central opacification in aspiration eyes over time since surgery. There were 14 aspiration eyes $(21 \%)$ where the primary capsulotomy was noted to be inadequate within the first month following surgery. In half of these cases the surgical capsulotomy was noted to be small or eccentric during the procedure, but the other half had a photographically documented adequate primary capsulotomy which later contracted. Nearly $40 \%$ of aspiration/primary capsulotomy eyes had significant axial capsule opacification within 6 months of surgery.

\section{Discussion}

GENERAL COMMENTS

The visual outcome of eyes with infantile onset cataracts is dependent on many factors such as type of cataract, age of onset, age at surgery, duration of opacity, and compliance with optical rehabilitation and occlusion. Although there are many reports on the visual outcome following surgery it is difficult to compare results as the type of cataract and management of cases varies greatly between studies (Table $4)$.

This trial was designed to determine the most suitable surgical treatment for children with bilateral cataract in south India. Randomised allocation of surgery to the first eye of each child was successful in ensuring comparability between the two groups and the difference in outcome between the two groups was therefore related to the surgery. A single

Table 4 Visual outcome following surgery for bilateral infantile cataract

\begin{tabular}{|c|c|c|c|c|}
\hline First author & $\begin{array}{l}\text { No of eyes in } \\
\text { study }\end{array}$ & Type of cataract & $\begin{array}{l}\text { Binocular vision better than } \\
6 / 18\end{array}$ & $\begin{array}{l}\text { Binocular vision less than } \\
6 / 60\end{array}$ \\
\hline Francois $^{19}$ & 167 & Incomplete & $70 \%$ & $17 \%$ \\
\hline Gelbart $^{20}$ & 48 & Incomplete & $60 \%$ & $27 \%$ \\
\hline Parks $^{21}$ & 32 & Incomplete & $100 \%$ & $0 \%$ \\
\hline Wright $^{22}$ & 44 & Incomplete & $73 \%$ & $2 \%$ \\
\hline Robb $^{23}$ & 38 & Incomplete & $73 \%$ & $18 \%$ \\
\hline Francois $^{19}$ & 100 & Total & $25 \%$ & $50 \%$ \\
\hline Neumann ${ }^{24}$ & 28 & Total & $78 \%$ & $0 \%$ \\
\hline Bradford $^{25}$ & 46 & Total & $43 \%$ & $14 \%$ \\
\hline Robb $^{23}$ & 26 & Total & $19 \%$ & $11 \%$ \\
\hline Lorenz $^{26}$ & 58 & Total & $33 \%$ & $25 \%$ \\
\hline This series & 112 & Mixture & $57 \%$ & $5 \%$ \\
\hline
\end{tabular}


Table 5 Secondary membranes complicating infantile cataract surgery

\begin{tabular}{llcl}
\hline Type of surgery & First author & No of eyes in series & $\begin{array}{l}\text { No of eyes developing } \\
\text { secondary membranes }\end{array}$ \\
\hline Aspiration alone & Chrousos $^{12}$ & 304 & $189(62 \%)$ \\
& France $^{27}$ & 77 & $29(47 \%)$ \\
& Taylor $^{18}$ & 28 & $19(68 \%)$ \\
& Parks $^{28}$ & 52 & $38(73 \%)$ \\
Aspiration and primary & Keech $^{8}$ & 20 & $15(75 \%)$ \\
capsulotomy & Chrousos $^{12}$ & 34 & $4(11.7 \%)$ \\
Lensectomy & Caputo $^{29}$ & 76 & $3(4 \%)$ \\
& This series $^{12}$ & 56 & $37(66 \%)$ \\
& Chrousos $^{12}$ & 54 & 0 \\
& Taylor $^{18}$ & 23 & 0 \\
& Green $^{30}$ & 52 & $6(11 \%)$ \\
& Keech $^{8}$ & 105 & $10(11 \%)$ \\
& This series & 56 & $1(2 \%)$ \\
\hline
\end{tabular}

surgeon undertook all of the procedures. The surgeon was familiar with the aspiration technique and also with lensectomy having performed more than 50 cases with each procedure before the trial. Follow up rates were high and because each eye was matched, losses were comparable between groups. Analysis by intention to treat (by operation allocated) was indistinguishable from analysis by operation performed.

Although children were only randomised if the cataracts were approximately symmetrical, the onset of the cataract in each eye could not be accurately determined. If the cataract in one eye had developed earlier and more rapidly than the other amblyopia is more likely to be present in the first eye affected. The randomisation procedure should reduce this bias. Delay in second eye surgery may increase the likelihood of amblyopia developing but the randomisation process meant that both procedures were equally likely to be delayed.

VISUAL OUTCOME

Overall, $94.6 \%$ of children achieved a binocular acuity of $6 / 60$ or better. There was no significant difference in visual outcome between the two techniques at the third year of follow up. If, however, secondary opacification of the posterior capsule had not been dealt with by YAG laser or surgical membranectomy the lensectomy group would have done better. This has relevance to the local population where good follow up is difficult to achieve and treatment may not always be available or affordable.

Nearly a third of children had lost or broken their spectacles in the first year following surgery. The problem of aphakic spectacles, particularly in preschool children, is an important barrier to good visual outcome and the role of intraocular lens implantation in this age group needs further evaluation. ${ }^{6}$

COMPLICATIONS

There were few complications related to the surgery from either group. There have been two cases of glaucoma detected (one lensectomy eye and one aspiration eye). The reported incidence of open angle glaucoma following cataract surgery in infants is anywhere between $5 \%$ and $24 \% .^{7-11}$ Open angle glaucoma appears to occur with equal frequency after lens aspiration or lensectomy ${ }^{9}{ }^{12}$ but so far no randomised clinical trials comparing surgical techniques on the incidence of open angle glaucoma have been published. Open angle glaucoma has been associated with microcornea and surgery at an early age. ${ }^{7813} \mathrm{We}$ expect to see cases developing over the next few years but the incidence may be lower in our study group because the children are older at initial presentation than in other groups studied.

Retinal detachment is a well recognised and usually late complication of cataract surgery in children. There have been two detachments so far, both occurred in lensectomy eyes (3.6\%). Occasionally detachments occur within a few months of surgery presumably related to vitreous traction exerted during the procedure but most detachments occur many years after surgery with an average delay of $20-30$ years $^{14}{ }^{15}$; the overall incidence may be as high as $10 \%{ }^{16}{ }^{17} \mathrm{~A}$ question that still remains unanswered is whether lensectomy with anterior vitrectomy will result in a higher or lower incidence of retinal detachment. ${ }^{18}$ The addition of an anterior vitrectomy may hasten the development of a posterior vitreous detachment, which may increase the risk of an earlier retinal detachment.

Our data show that eyes that had a lensectomy required fewer secondary procedures than those that had an aspiration and primary capsulotomy. Data from other series show that the aspiration technique without primary capsulotomy results in a $47-75 \%$ secondary opacification rate, aspiration with primary capsulotomy a $4-12 \%$ rate $(66 \%$ in our series which is likely to be due to a small primary capsulotomy combined with a marked inflammatory reaction in pigmented eyes), and lensectomy $0-11 \%$ ( $2 \%$ in our series) (Table 5).

\section{CONCLUSION}

A recent workshop on childhood blindness estimated that of 1.4 million blind children worldwide, $130000-200000$ is due to cataract - that is, an average of $20-30$ blind children from cataract per million total population. ${ }^{31}$ The incidence of bilateral nontraumatic cataract is estimated to range from $20000-40000$ cases per year. ${ }^{32}$

This clinical trial has shown that if follow up to manage posterior capsule opacification and maintain spectacle correction is available then good visual outcome can be achieved with lens aspiration. Lensectomy has the advantage of not commonly requiring further surgical interventions. There were more problems with the surgical technique and maintenance of equipment in this series of lensectomy cases, which may relate to the equipment that was available for the procedure. The role of intraocular lenses in young children with cataract in developing countries needs evaluation as this could obviate the problem of lost and broken aphakic spectacles. It is planned to follow this cohort for a further 7 years in order to assess late complications, particularly from glaucoma.

This study was supported by Sightsavers International and the British Council for Prevention of Blindness. 
1 Rahi JS, Sripathi S, Gilbert CE, et al. Childhood blindness in India: causes in 1318 blind school students in nine

Jain IS, Pillai P, Gangwar DN, et al. Congenital cataract: management and results. F Pediatr Ophthalmol Strabismus 1983;20:243-6

3 Eckstein MB, Vijayalakshmi P, Killedar M, et al. Aetiology of childhood cataract in south India. $\mathrm{Br} \mathcal{f}$ Ophthalmol 1996;80:628-32.

4 Droste PJ, Archer SM, Helveston EM. Measurement of low vision in children and infants. Ophthalmology 1991;98: 1513-18.

5 Thompson JA. The chi-squared test for data collected on eyes. Br F Ophthalmol 1993;77:115-17.

6 Eckstein M, Vijayalakshmi P, Killedar M, et al. Use of intraocular lenses in children with traumatic cataract in south India. Br f Ophthalmol 1998;82:911-15.

7 Egbert JE, Wright MM, Dahlhauser KF, et al. A prospective study of ocular hypertension and glaucoma after paediatric study of ocular hypertension and glaucoma after paediat
cataract surgery. Ophthalmology 1995;102:1098-101.

8 Keech RV, Tongue AC, Scott WE. Complications after surgery for congenital and infantile cataracts. [Review] $\mathrm{Am} \mathcal{F}$ Ophthalmol 1989:108:136-41.

9 Mills MD, Robb RM. Glaucoma following childhood cataract surgery. F Pediatr Ophthalmol Strabismus 1994;31:35560; discussion 361 .

10 Robb RM, Petersen RA. Outcome of treatment for bilateral congenital cataracts. Ophthalmic Surg 1992;23:650-6.

11 Simon JW, Mehta N, Simmons ST, et al. Glaucoma after pediatric lensectomy/vitrectomy. Ophthalmology 1991;98 $670-4$.

12 Chrousos GA, Parks MM, O’Neill JF. Incidence of chronic glaucoma, retinal detachment and secondary membrane surgery in pediatric aphakic patients. Ophthalmology 1984; 91:1238-41.

13 Parks MM, Johnson DA, Reed GW. Long-term visual results and complications in children with aphakia. A function of cataract type. Ophthalmology 1993;100:826-40; distion of cataract
cussion 840 .

14 Jagger JD, Cooling RJ, Fison LG, et al. Management of retinal detachment following congenital cataract surgery. Trans nal detachment following congenital
Ophthalmol Soc UK 1983;103:103-7.

15 Toyofuku H, Hirose T, Schepens CL. Retinal detachment following congenital cataract surgery. Arch Ophthalmo 1980;98:669-75.

16 Kanski JJ, Elkington AR, Daniel R. Retinal detachment after congenital cataract surgery. Br f Ophthalmol 1974;58:92-5.
17 Shapland CD. Retinal detachment in aphakia. Trans Ophthalmol Soc UK 1934;54:176-96.

18 Taylor D. Choice of surgical technique in the management of congenital cataract. Trans Ophthalmol Soc UK 1981;101: $114-17$.

19 Francois J. Late results of congenital cataract surgery. Ophthalmology 1979;86:1568-98.

20 Gelbart SS, Hoyt CS, Jastrebski G, et al. Long term visual results in bilateral congenital cataracts. Am $\mathcal{F}$ Ophthalmol 1982;93:615-21.

21 Parks MM. Visual results in aphakic children. Am $\mathcal{f}$ Ophthalmol 1982;94:441-9.

22 Wright KW, Christensen LE, Noguchi BA. Results of late surgery for presumed congenital cataracts. Am f Ophthalmol 1992;114:409-15.

23 Robb RM, Petersen RA. Outcome of treatment for bilateral congenital cataracts. Trans Am Ophthalmol Soc 1992;90: 183-94; discussion 194.

24 Neumann D, Weissman BA, Isenberg SJ, et al. The effectiveness of daily wear contact lenses for the correction of infantile aphakia. Arch Ophthalmol 1993;111:927-30.

25 Bradford GM, Keech RV, Scott WE. Factors affecting visual outcome after surgery for bilateral congenital cataracts. $\mathrm{Am}$ f Ophthalmol 1994;117:58-64.

26 Lorenz B, Worle J. Visual results in congenital cataract with the use of contact lenses. Arch Clin Exp Ophthalmol 1991;22:123-32.

27 France TD. Management of the posterior capsule in congenital cataracts. F Pediatr Ophthalmol Strabismus 1984; 21:116-17.

28 Parks MM, Hiles DA. Management of infantile cataracts. Am f Ophthalmol 1967;63:10-20.

29 Caputo AR, Guo S, Wagner RS, et al. A modified extracapsular cataract extraction for pediatric cataracts. Ophthalmic Surg 1990;21:396-400.

30 Green BF, Morin JD, Brent HP. Pars plicata lensectomy/ vitrectomy for developmental cataract extraction: surgical results. F Pediatr Ophthalmol Strabismus 1990;27:229-32.

31 Task Force Informal Consultation with WHO on the Strategies for Prevention of Blindness in Children. Geneva: WHO, 1998.

32 Foster A, Gilbert C, Rahi J. Epidemiology of cataract in childhood: a global perspective. $\mathcal{F}$ Cataract Refractive Surg 1997;23:Suppl 1. 